\title{
Aesthetic Features of Decorations on Purple Pottery in Jianshui
}

\author{
Tingyu Su \\ ${ }^{1}$ Depart of art, Baoshan university, Baoshan, China \\ awenhua1711@qq.com
}

Keywords: Jianshui Purple Pottery, Aeshetic Feature, Decoration of painting and calligraphy.

\begin{abstract}
Yunnan Jianshui formed a distinctive regional culture in the collision and absorbing process between the Central Plains culture and national culture. Purple Pottery culture bred in this unique cultural soil has its special aesthetic sense. It cleverly combines practical use to art, and with the understanding of cultural life and appreciation of life philosophy, it shows the aesthetic value of Jianshui Purple Pottery.
\end{abstract}

\section{Introduction}

The immigrant culture in Yunnan Jianshui was born in the collision and absorbing process between national culture and the Central Plains culture. The unique Jianshui culture today, not only shows its worship towards its root, the Han culture, but also differs from the pure Central Plains culture style [1]. The special Purple Pottery culture is bred in this unique cultural soil of Jianshui. For Jianshui people, the special aesthetic sense, the clever combination of practical use and art, the unique understanding of cultural life and the appreciation of life philosophy of Jianshui Purple Pottery has the Confucious beauty of neutral and powerful, free and tranquil, the moralistic beauty of quiet and spiritual, being and not-being, and the Zen beauty of light and full, far and detached. The workmanship of Jianshui Purple Pottery follows aesthetic principles [2]. The solemn, elegant, simple and refined shape is achieved through factors such as shape, color, emblazonment and so on. The beauty of shape is in accordance with the regional culture character in Jianshui. When people hold the Purple Pottery in hands to admire them, they usually identify the material, listen to the ring, observe the color and admire the decoration. The graceful shape and unique craft skills make the Purple Pottery distinguish and reflect craftsman's persistent exploration of skill and pursuit of better life.

\section{Its shape embodies its doctrine as well as the beauty of symmetry}

The beauty of its shape is the primary beauty of Jianshui purple pottery. Jianshui was greatly affected by the central plain culture which spreads Confucianism and advocates elegance. Consequently, the Jianshui Purple Pottery emphasizes symmetric and harmonious shape, smooth and stretching line. The most refined Jianshui Purple Pottery is steady, implicit, well balanced and delicate The rational, delicate and complex making process of Purple Pottery is filled with the pure and warm emotion of the artists. The shape of the Jianshui Purple Pottery naturally blends circle and square, converts point and line, holds adequate body size, thus creating a spatial relationship that combines circle and square, virtual and real, density and sparse. The classical pottery always contains tactful and harmonious change, which can be described as natural and to the point. As an embodiment of the perfect combination of form and ideology, the Purple Pottery condenses not only the creating idea of the good pure folk culture and the oriental aesthetics of literati but also the characters and life pursuit of the creator.

Common shapes of Jianshui Purple Pottery all evolve from the most basic shape-circle. Round-based Purple Pottery has many merits, such as easy to shape, large capacity and solidness. As a basic shape, circle creates a sense of security and stability that people are more willing to accept, which is worldly recognized. Ancient Greek philosopher Pythagoras once said that "the circle and the sphere are the earliest beautiful shape that people ever found". [3]The main shape of Jianshui Purple Pottery is to show the beauty of symmetry. For example, Xiang Fengchun, the 
famous artist of Jianshui Purple Pottery, made a pottery called "binaural beast Bogu bottle”. The upper opening is a big circle and the lower part is a thin column. The shape is coherent, harmonious, symmetric, soft, smooth and in good proportion, which demonstrate a simple, plain and steady style and embodies the Chinese classical style.

When the ceramic art becomes mature, the shape is bound to become stylized. This phenomenon marks that the art reaches a representative high level in a more mature stage of development, or in some aspects of special skills. The Jianshui Purple Pottery, which includes straight mouth bottles, beautiful bottle, garlic bottle, vase, boilers, pipes, etc., has a relatively fixed shape and is famous for plainness. It is plainness that makes its shape unique.

\section{Its texture has the gentility of jade}

The Yunnan jade-like texture is a very important artistic feature of Jianshui Purple Pottery. Visually, Purple Pottery is symmetric and elegant while for touch it is exquisite and soft like jade. Different from other pottery and porcelain which requires glazing after firing, Jianshui Purple Pottery has very exquisite clay as fine as cream butter and it do not need glazing and therefore it is natural. After firing, the pottery will get a variety of textures through the grinding process. But the grinding process is time-consuming and need a lot of work.

Because the clay of Jianshui Purple Pottery contains more iron than other clay, the surface of the fired pottery takes on a metal -like luster and fine sand -like texture. With the gravel being grinded from coarse to fine, the metal -like luster gradually disappear and become smooth, the same as the process that the mountain fog fade away. The more grinding it gets, the better and brighter it becomes. By controlling the degree of grinding, the pottery can have different textures of dull polish or matte until it is as smooth and bright as a mirror. Also a variety of techniques of grinding can be used on the same pottery to produce more extensive and changing sensual experience on different parts of the surface of the pottery and at different levels. After the grinding, the pottery will present an archaic, simple or elegant texture and it looks like a beautiful jade and feels like the skin of babies. Because Purple Pottery does not need glazing, its beautiful texture does not depend on the glazed color and the luster varies according to the capacity and shapes. Some are as colorful as rosy clouds and some are as smooth as mirror. They are elegant, archaic, implicit, soft or natural. The unique natural beauty of the clay is perfectly presented after high-temperature calcination and it shows the essential features of the Purple Pottery being as elegant, classical, quiet and gentle as jade to the largest degree.

The daily maintenance of Jianshui Purple Pottery can not be ignored just like the gentleman should cultivate his moral character and keep a low profile. If maintained properly, the texture of new Jianshui Purple Pottery will gradually change. Soaked by the tea juice for years, the carefully maintained teapot will take on a softer and more gentle luster than that of the time when the grinding is not finished and the texture will become more mild and exquisite, which makes the pottery not only suitable for daily use but also for taste and appreciation. Just as an energetic boy, after years of baptism and experience, he becomes gentle and modest.

\section{It has the acoustic beauty of the chime}

Great Music can not be heard and gorgeous beauty can not be seen. The clay of the Jianshui Purple Pottery comes from nature without the coarseness of sand and stone. Through the cooperation of artists, the shape of the pottery becomes natural and the calligraphy and painting embodies its soul. Burning makes the pottery as hard as iron and honing demonstrates the metallic and stone-like beauty of the pottery. ( Figure 1)

Purple Pottery making process includes selecting materials, manufacturing clay, making embyro, drawing, engraving and coloring, modifying, firing, polishing, etc. among which the firing process is the key step to transform the clay embryo from soft to hard and to make the clay as strong as stone and metal and enhance the beauty of the pottery after the former process. The whole process combine with each other so closely that whatever step goes wrong even that a grain of sand 
is not filtered will destroy the firing process and all the previous efforts waste. So the artists should cooperate in concerted efforts in every step and every detail to concentrate their wisdom and labor to achieve success through tacit collaboration. Just as the saying goes "good faith moves mountains", the aesthetic pursuit of simulating nature while transcending nature sublimates Purple Pottery art.

Only the pottery that are well-made and fired enough can emit jingle-like, harmonious and elegant sound when tapping it softly. The shape of Purple Pottery depends on its application, but whatever shape it has, it will emit rhythmic, powerful, harmonious, extensive and impressive sound. The making process of Jianshui Purple Pottery is also a process in which people pursue the harmony of nature and it reveals the gentility, elegance, confidence, resolution and life ideas of the Jianshui people. It stands for not only the simple cognition of Chinese people for heaven, earth and human but also the understanding of the law of nature and realm of life. The best Purple Pottery embodies the beauty of landscape, the glory of the sun and the moon and can be compared with metal and stone. It is archaic, natural, elegant and noble. The beauty of the sound of the Jianshui Purple Pottery lies in its respect for nature, combination of skill and art, unity and cultivation of both form and spirit, and thus is the externalization of the beauty of the Jianshui Purple Pottery art.

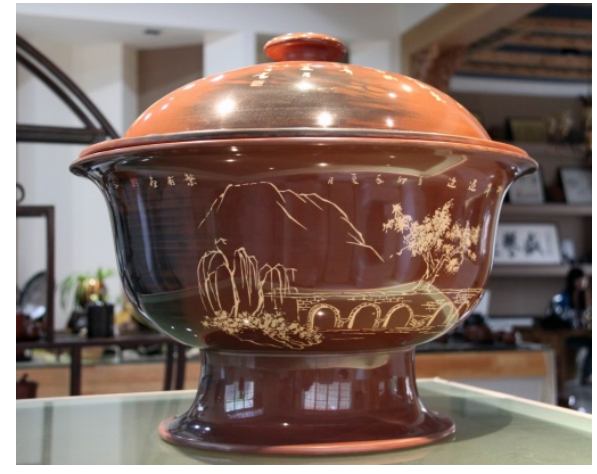

(a)

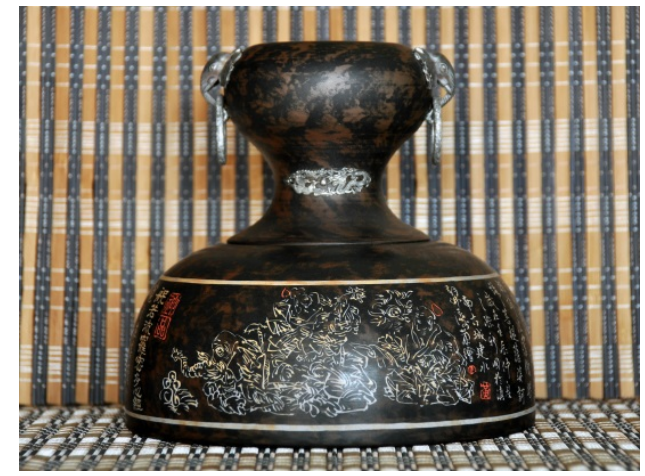

(b)

Fig. 1 Burning makes the pottery as hard as iron and honing demonstrates the metallic and stone-like beauty of the pottery

\section{Its color has the gorgeous beauty of rosy clouds}

Jianshui Purple Pottery decoration is completed all by hand and the color difference is achieved by using clay of different colors. Jianshui Purple Pottery has abundant and changing colors that resemble rosy clouds. It has both light and dark red, cold and warm brown, bright and shadowy white. Generally speaking, in the natural state, Jianshui Purple Pottery has red, white, green, yellow, brown and other colors; after firing, among many colors including red, white, gray, yellow, brown, black, purple on the pottery, the most representative color is the reddish brown (commonly known as liver red) and white yellow (also known as ivory white), which are produced by the oxidizing flame and the pottery is made of red or white clay. Reddish brown and white yellow are the two main colors, but if the method of firing is skillfully controlled, the degree of lightness and brightness of the same color will change. If clay and powder of different colors are mixed in proportion, the Purple Pottery will take on more than a hundred colors, such as liver color, ivory, pale, gray, incense gray, maroon, copper-colored, mud red, green brown, dark brown, black paint, pomegranate skin color and so on. Because these colors are formed by mixing different colors of clay and powder, the Jianshui Purple Pottery has its natural beauty in spite of its very abundant colors. The color of the Jianshui Purple Pottery is changeful in hue and lightness and has a natural transition, but the colorful degree is unified. As a result, the color is characterized by purity, elegance and antiquity.

The craft of firing of the Purple Pottery is also responsible for its protean colors. When the temperature inside the kiln reaches $1200^{\circ}$, the Purple Pottery will show a wonderful fambe, namely, 
[4] purple and red appears on the same pottery, which is either black or red, red or deep red and likes the most uncertain and mysterious colors of the rosy clouds. This kind of fambe is so fascinating and appealing that the color of the pottery is unified when it is not yet in the kiln while the color becomes so protean after it is taken out of the kiln.

The process in which the color is firstly implanted in the pottery and finally be in harmony with the pottery after the firing reveals the indispensable aesthetic value and significance of the Purple Pottery and embodies the ideology and humanistic feelings as an unique artistic language.

\section{Its decoration has the flexibility and liveliness of the smoke}

Finally fired successfully and attaining an elegant appearance, the Jianshui Purple Pottery is enhanced in value by the artistic decoration. The perfect combination of the elegant model with the decoration of calligraphy and painting on the pottery makes it unified in form and spirit.

The decoration of traditional Jianshui Purple Pottery usually adopts artistic forms such as poetry, calligraphy, painting, carving and so an. Recently, there are some experimental art attempts such as engraving, plating, twisted clay, clay painting, decals, relief, mosaic, color glaze. More and more famous painters and calligrapher have participated in the creation of Purple Pottery.

Chen Hongling, a painter and calligrapher at Yunnan Art Institute, likes to have Buddhist themes within his painting and calligraphy work and on the decoration of the Purple Pottery [5]. His lively, captivating, ethereal as smoke, coherent and accessible works are seen as the best among the many painting and calligraphy decoration and are popular among lovers of Purple Pottery painting, which greatly improves the value of his works.

The Purple Pottery works of painter and calligrapher Su Fotao is also among the best. His calligraphy is unrestrained, bold, powerful and smart, old-fashioned Lohan lifelike and archaic, ladies innocent and lyric, flowers, birds, fish and insects elegant and mild, landscape unrestrained and refined. In 2012, China (Kunming), the first session of Intoxicating China - Chinese Pottery Art Festival and the sixth session of Kunming Pan Asia International Folk Crafts Fair awarded the "Hani pot" and "new boiler"decorated by Su Fotao gold prize. The new "Yunnan 18 oddities" decoration on the Hani pot that has unique ethnic flavor makes the characters more vivid and thus fully demonstrates its ethnic characteristics. The content of the calligraphy together with the decoration is so closely combined to the traditional cooking function of the pottery that it is fascinatingly natural, and therefore appeals to our interest.

The content of Purple Pottery painting and calligraphy not only demonstrates the author's aesthetic ideas and philosophy of life, but also has the function of spreading traditional culture, ethics and morals. Indeed, craft is to convey ideas. Pottery and ideas are a unified whole.

\section{References}

[1] B.Y. Wu, The Forming Reasons and Negative Effect of Painting and Calligraphy Decorations on Jianshui Pottery, National Art Studies,(3)2011.150-160.

[2] B.C. Xiang and J. Dai, The Beauty of Jianshui Purple Pottery in Transmutation, Today's Nations,(7)2011.24-25.

[3] J. Shao, K.X. Wang and R.P Xu, The Art of Painting and Calligraphy Decoration on Jianshui Purple Pottery, Science and Art in Pottery,(1)2009.29-31.

[4] M.L Nie, Exploration of Shape Art in Jianshui Purple Pottery, The Front, (6)2012.132-133..

[5] R. Tian, Creation of Artistic Living Space-An Essay on Pottery in Daily Life, Journal of Zhengzhou Light Industry Academy,(6)2005.46-49. 